\title{
Thermal Decomposition Behaviour of Bis(4-Nitrophenol)-2,4,6-Triamino-1,3,5-Triazine Monohydrate
}

\author{
N. Kanagathara ${ }^{a}$, M.K. MarchewkA ${ }^{b}$ And G. Anbalagan ${ }^{c, *}$ \\ ${ }^{a}$ School of Basic Sciences, Vel Tech University, Chennai-62, India \\ ${ }^{b}$ Institute of Low Temperature and Structure Research, Polish Academy of Sciences, \\ P.O. Box 937, 50-950 Wrocław 2, Poland \\ ${ }^{c}$ Department of Nuclear Physics University of Madras Guindy Campus Chennai-600025 \\ (Received October 12, 2015; in final form May 2, 2016)
}

\begin{abstract}
Thermal decomposition behavior of bis (4-nitrophenol)-2,4,6-triamino-1,3,5-triazine monohydrate (BNPM) has been studied by means of thermogravimetric analysis at three different heating rates 10,15 and $20^{\circ} \mathrm{C}$ min ${ }^{-1}$. Non-isothermal studies of BNPM have revealed that the decomposition occurs in three stages involving dehydration and decomposition. The values of effective activation energy $\left(E_{\mathrm{a}}\right)$, pre-exponential factor $(A)$ of each stage of thermal decomposition for all heating rates were calculated by model free methods: Arrhenius, Flynn-Wall, Friedman, Kissinger and Kim-Park method. A significant variation of effective activation energy $\left(E_{\mathrm{a}}\right)$ with conversion $(\alpha)$ indicates that the process is kinetically complex. The linear relationship between the $A$ and $E_{\mathrm{a}}$ values was well established (compensation effect). Dehydration stage was governed by the Avrami-Erofeev model (A2) and decomposition stages were governed by the Avrami-Erofeev model (A4).
\end{abstract}

DOI: 10.12693/APhysPolA.129.1235

PACS/topics: 83.60.St, 87.15.R-, 91.60.Ki, 82.20.Pm

\section{Introduction}

Melamine $(2,4,6$-triamino-1,3,5-triazine) is an industrial chemical mainly used in the production of melamine formaldehyde resins for surface coatings, laminates, adhesives, and automobile paints [1,2]. Melamine and its salts are widely used in the formulation of fire retardant additive systems for polymeric materials $[3,4]$. Nitrophenolic compounds are used as explosives, azo dyes, fungicides, insecticides, herbicides and pharmaceuticals [5]. Both melamine and phenols are used in the manufacture of formaldehyde resins for surface coatings and as bonding agents in the laminated products among other uses. Many researchers reported the kinetic behavior of melamine as well as $p$-nitrophenol molecules [6-8]. Several researchers have already studied the thermal behavior of melamine and its salts [9-16]. The decomposition behavior of melamine phosphate, melamine cyanurate and melamine-formaldehyde resins are reported by many authors [17-20]. Kinetics of the curing process of alkyd-melamine resin systems was reported by Filipovic et al. [21]. Thermal decomposition kinetics as well as thermal stability of polymers and its composites can be studied by either single heating rate program like Coats-Redfern, Freeman-Caroll, Chang or multiple heating rate programs like Friedman, Flynn-Wall, Kissinger and Kim-Park [22-24]. Kanagathara et al. [25, 26] reported the structural, optical, mechanical, dielectric

*corresponding author; e-mail: anbu246630yahoo.co.in and thermal studies of an organic-organic melamine salt (BNPM). This is for the first time, we report the nonisothermal decomposition behavior of the BNPM organic salt by different isoconversional multiple heating methods; since this method has no assumption about the reaction order in the calculation of activation energy, also yields less error than the single heating rate method, the Flynn-Wall, Friedman, Kissinger and Kim-Park. Also, in this work, the Arrhenius parameters (activation energy and pre-exponential factor) of thermal decomposition of BNPM were studied. Results are presented and discussed in detail.

\section{Experimental details}

BNPM was synthesized from AR grade samples of melamine and $p$-nitrophenol in the stoichiometric ratio $1: 1$ by slow evaporation method. The double distilled water was used as a solvent. To the hot solution of melamine, $p$-nitrophenol solution was added gently, stirred continuously well for $5 \mathrm{~h}$ to get the homogeneous solution and then allowed to cool at room temperature. The purity of the synthesized salt was further improved by re-crystallization process. Tiny, transparent, yielded yellowish crystals were grown in a growth period of 25 30 days.

\subsection{Characterization}

The grown crystals of BNPM was subjected to single crystal X-ray diffraction (XRD) analysis using ENRAF Nonius AD4/MAC4 X-ray diffractometer with Mo $K_{\alpha}$ $(\lambda=0.71073 \AA)$ radiation. The grown crystals have also been characterized by X-ray powder diffraction technique using Rich Seifert X-ray powder diffractometer 
with $\mathrm{Cu} K_{\alpha}$ radiation of $\lambda=1.5406 \AA$. The $\theta$ range was analyzed from $10^{\circ}$ to $70^{\circ}$ by employing the reflection mode for scanning. The detector used was a scintillation counter. The thermal behavior of BNPM was studied at 10,15 and $20^{\circ} \mathrm{C} \min ^{-1}$ by using a SDT Q $600 \mathrm{~V} 8.2$ Built 95 thermal analyzer. The experimental conditions were: (a) continuous heating from room temperature to $800^{\circ} \mathrm{C}$ for 10,15 and $20^{\circ} \mathrm{C} \mathrm{min}^{-1}$; (b) nitrogen gas dynamic atmosphere $\left(90 \mathrm{~cm}^{3} \mathrm{~min}^{-1}\right)$; (c) alumina, crucible; (d) sample of mass: $2.9240,3.4540$, and $2.6710 \mathrm{mg}$ for 10,15 , and $20^{\circ} \mathrm{C} \min ^{-1}$, respectively.

\section{TG kinetics method of degradation}

Thermal gravimetric (TG) kinetics analysis is determined by measurement of fractional mass loss and degradation rate according to temperature change. The fraction of conversion $\alpha$ is defined as:

$$
\alpha=\left(W_{0}-W\right) /\left(W_{0}-W_{\mathrm{f}}\right),
$$

where $W$ is the actual mass at any degradation time, $W_{0}$ is the initial mass, and $W_{\mathrm{f}}$ is the final mass at the end of thermal degradation process. The rate of degradation, $\mathrm{d} \alpha / \mathrm{d} t$, can be expressed as the product of the function of temperature and the function of conversion [27]:

$$
\mathrm{d} \alpha / \mathrm{d} t=k(T) f(\alpha),
$$

where $k(T)$ is the rate constant and $f(\alpha)$ is the reaction model which describes the dependence of reaction rate on the extent of reactions.

If thermal degradation behavior follows the Arrhenius equation, then $k(T)$ is expressed as

$$
k(T)=A \exp \left(-E_{\mathrm{a}} / R T\right),
$$

where $E_{\mathrm{a}}$ is activation energy, $A$ is a pre exponential factor and $R$ is the gas constant.

For non-isothermal experiments, the reaction rate at all times depends on both $f(\alpha)$ and $k(T)$. Hence generally $f(\alpha), E$ and $A$ are known as kinetic triplet.

The temperature dependent function is generally assumed to follow an Arrhenius type dependence [27]:

$$
\ln k=\ln A-E_{\mathrm{a}} / R T \text {. }
$$

\subsection{Flynn-Wall method}

This is the simplest method for determining activation energies directly from mass loss against temperature obtained at several heating rates. This technique assumes that $A,(1-\alpha)^{n}$ and $E_{\mathrm{a}}$ are independent of $T ; A$ and $E_{\mathrm{a}}$ are independent of $\alpha$. The Flynn-Wall plot is obtained by using the following expression [28]:

$$
\ln \beta=\ln \left(A E_{\mathrm{a}} / R\right)-\ln F(\alpha)-E_{\mathrm{a}} / R T .
$$

The value of the activation energy $\left(E_{\mathrm{a}}\right)$ can be calculated from the slope of the plot between $\ln \beta$ vs. $1 / T$ for a fixed mass loss. This method cannot give the other kinetic parameters except for the activation energy.

\subsection{Friedman method}

The differential isoconversional method suggested by Friedman [29] is based on Eq. (6):

$$
\ln (\mathrm{d} \alpha / \mathrm{d} t)=\ln A+n \ln (1-\alpha)-E_{\mathrm{a}} / R T .
$$

This is the simplest method and it assumes that degradation process is independent of temperature and depends only on the instantaneous weight of the material. $E_{\mathrm{a}}$ can be obtained from the slope $\left(=-E_{\mathrm{a}} / R\right)$ of plot $\ln (\mathrm{d} \alpha / \mathrm{d} t)$ versus $1 / T$ for a constant $\alpha$.

\subsection{Kissinger method}

The activation energy for the non-isothermal decomposition of BNPM was calculated from the TG data for the stages I, II, and III by using the Kissinger expression $[30]$ :

$$
\ln \left(\beta / T_{\mathrm{p}}^{2}\right)=\ln \left(n\left(1-\alpha_{m}\right)^{n-1} A R / E_{\mathrm{a}}\right)-E_{\mathrm{a}} / R T_{\mathrm{p}},
$$
where $\beta$ is the heating rate, $A$ is the pre-exponential factor, $E_{\mathrm{a}}$ is the energy of activation, $R$ is the gas constant, $T_{\mathrm{p}}$ is the absolute temperature at the maximum rate of thermal decomposition and $\alpha_{m}$ is the mass loss at the maximum decomposition rate. The Kissinger method [30] assumes that $\ln \left(1-\alpha_{m}\right)^{n-1}$ is independent of the heating rate. It also assumes that the reaction order remains constant, and is very nearly equal to unity. The value of the activation energy can be calculated from the slope of the plot of $\ln \left(\beta / T_{\mathrm{p}}^{2}\right)$ vs. $1 / T_{\mathrm{p}}$ at the maximum mass loss.

\subsection{Kim-Park method}

The Kim-Park method [31] assumes that $\alpha_{m}$ is independent of the heating rate $\beta$, activation energy $E_{\mathrm{a}}$, and a pre-exponential factor $A$.

$$
\ln \beta=\ln Z+\left(E_{\mathrm{a}} / R\right)+\ln (1-n+(n / 0.944)) .
$$

The activation energy can be obtained by plotting $\ln \beta$ against $1 / T_{\mathrm{p}}$. Since the conversion factor is taken as unity, this method can be considered as more accurate than the other methods.

\section{Results and discussion \\ 4.1. Single crystal diffraction analysis}

Single crystal XRD analysis confirms that BNPM crystallizes in the triclinic $(P-1)$ system and the calculated lattice parameters are $a=7.123(5) \AA, b=10.577(4) \AA$, $c=13.680(5) \AA, \alpha=68.256(5)^{\circ}, \beta=88.772(6)^{\circ}$, $\gamma=76.604(5)^{\circ}$ and $V=928.9(8) \AA^{3}[25]$.

\subsection{X-ray powder diffraction analysis}

Figure 1 shows the indexed X-ray powder diffraction pattern of BNPM. From the X-ray powder diffraction

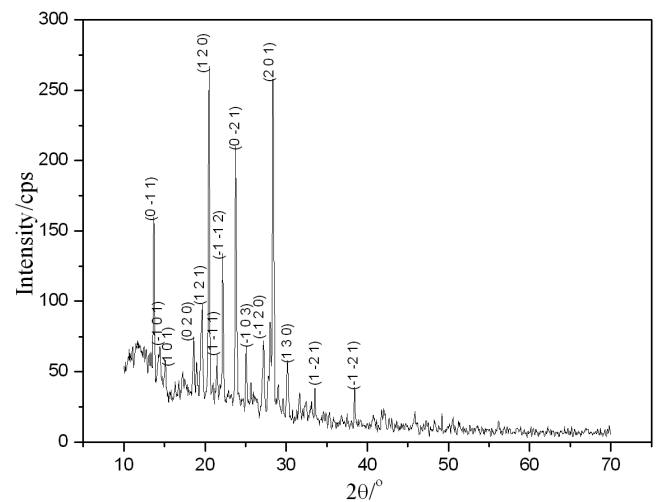

Fig. 1. X-ray powder diffraction pattern of BNPM. 
data, the lattice parameters and the unit cell volume have been calculated as $a=7.167 \pm 0.070 \AA, b=$ $10.242 \pm 0.040 \AA, c=13.055 \pm 0.224 \AA, \alpha=72.29 \pm 0.29^{\circ}$, $\beta=88.72 \pm 0.46^{\circ}, \gamma=74.80 \pm 0.27^{\circ}$ and $V=879.20 \AA^{3}$. The data reveal a close agreement with the reported values [25] and the values obtained from the single crystal $\mathrm{X}$-ray diffraction of the present work.

\subsection{Thermal analysis}

TG-DTG curves of BNPM at three different heating rates 10,15 and $20^{\circ} \mathrm{C} \min ^{-1}$ are depicted in Fig. 2 .

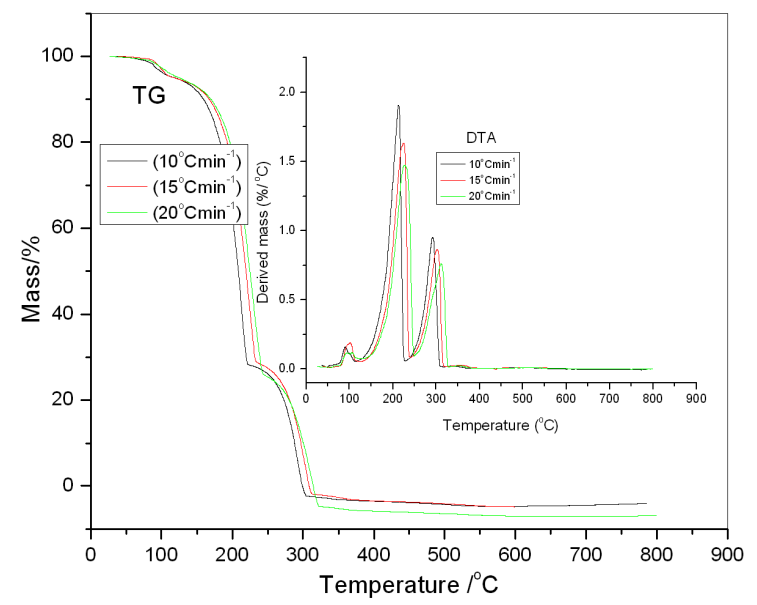

Fig. 2. TG-DTA curves of BNPM in nitrogen atmosphere; heating rate of 10,15 , and $20^{\circ} \mathrm{C} \mathrm{min}{ }^{-1}$.

The TG curve exhibits mass losses in three stages. For $10^{\circ} \mathrm{C} \mathrm{min}^{-1}$, the initial mass is taken as $2.9240 \mathrm{mg}$. The first stage of decomposition takes place in the temperature range from $88.45^{\circ} \mathrm{C}$ to $109.43^{\circ} \mathrm{C}$ with a weight loss about $5.550 \%$ is due to the liberation of one water molecule. The corresponding endothermic peak is seen at $93.45^{\circ} \mathrm{C}$. A rapid mass loss starts at $199.28^{\circ} \mathrm{C}$ and continues up to $240.84^{\circ} \mathrm{C}$ with a mass loss about $69.09 \%$. It is exactly matched with an endothermic peak at $225.95^{\circ} \mathrm{C}$ in differential thermal analysis (DTA) curve which is attributed to the decomposition of two $p$-nitrophenol molecules from the structure of the compound. The third stage of mass loss occurs in the range from $288.26^{\circ} \mathrm{C}$ to $320.32{ }^{\circ} \mathrm{C}$ with a mass loss about $30.26 \%$ due to the decomposition of melamine. It is accompanied by an endothermic peak at $312.67^{\circ} \mathrm{C}$.

TABLE I

Theoretically expected and observed decomposition percentage of BNPM.

\begin{tabular}{c|c|c}
\hline \hline \multirow{2}{*}{ Products } & \multicolumn{2}{|c}{ Percentage [\%] } \\
\cline { 2 - 3 } & Expected & Observed \\
\hline water & 4.27 & 5.55 \\
two nitrophenol & 65.87 & 69.09 \\
melamine & 30.26 & 29.86
\end{tabular}

The similar peaks of melaminium cation occurs at $296.04{ }^{\circ} \mathrm{C}$ for melaminium bis hydrogen oxalate [32]; at $302.27^{\circ} \mathrm{C}$ for melaminium bis(trifluoroacetate) trihydrate [33]; at $325^{\circ} \mathrm{C}$ for melamine-3-nitrophenol complex [34]; at $322.86^{\circ} \mathrm{C}$ for melamine-acrylic acid complex [35]. The very good agreement between the expected and observed mass loss for the loss of one water molecule, two $p$-nitrophenol and one melamine molecule is shown in Table I. When the heating rate is increased to 15 and $20^{\circ} \mathrm{C} \min ^{-1}$, all endothermic peaks in DTG curve are shifted to higher temperatures which is clearly seen in Fig. 1. Thus, the heating rate influences the thermal decomposition of BNPM [36].

A typical plot of $\alpha$ versus temperature for stages I, II and III is shown in Fig. 3. It is seen that all $\alpha-T$ curves have the same shapes.

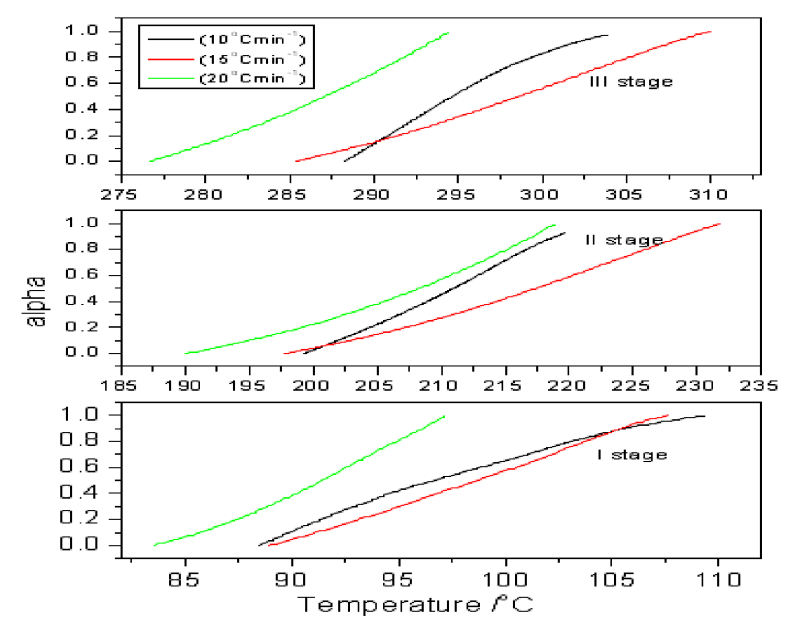

Fig. 3. Fraction reacted, $\alpha$ versus temperature for stages I, II and III at three heating rates.

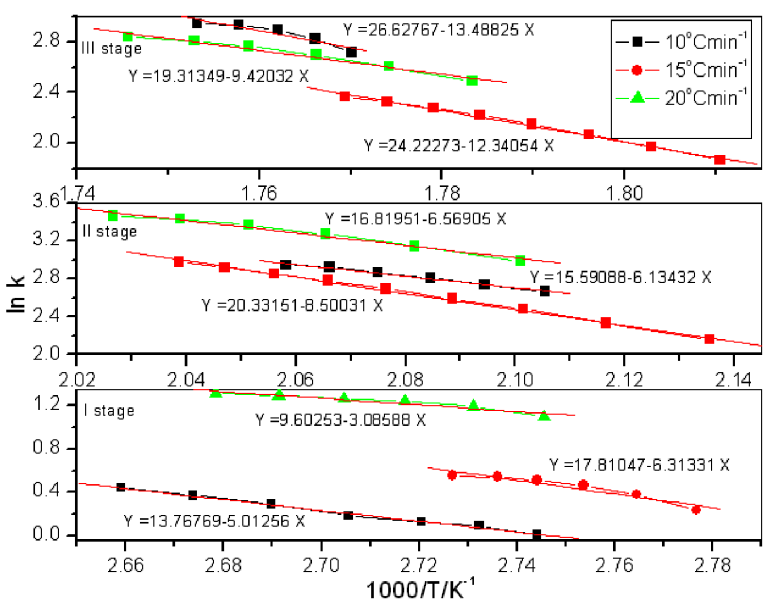

Fig. 4. Arrhenius plots of $\ln k$ versus temperature for non-isothermal decomposition of BNPM for stages I, II and III.

The linear Arrhenius plots of $\ln k$ versus $1 / T$ for the thermal decomposition of BNPM at three different heating were plotted in Fig. 4 from the non-isothermal TG 
TABLE II

Activation energies of thermal degradation of BNPM by Arrhenius, Kissinger and Kim-Park method.

\begin{tabular}{c|c|c|c|c|c|c|c}
\hline \hline \multirow{3}{*}{ Method } & \multirow{2}{*}{$\begin{array}{c}\text { Heating } \\
\text { rate } \\
{\left[\frac{{ }^{\circ} \mathrm{C}}{\mathrm{min}}\right]}\end{array}$} & \multicolumn{2}{|c|}{ Stage I } & \multicolumn{2}{c|}{ Stage II } & \multicolumn{2}{c}{ Stage III } \\
\cline { 3 - 8 } & $\begin{array}{c}E_{\mathrm{a}} \\
{\left[\frac{\mathrm{kJ}}{\mathrm{mol}}\right]}\end{array}$ & $\ln A$ & $\begin{array}{c}E_{\mathrm{a}} \\
{\left[\frac{\mathrm{kJ}}{\mathrm{mol}}\right]}\end{array}$ & $\ln A$ & $\begin{array}{c}E_{\mathrm{a}} \\
{\left[\frac{\mathrm{kJ}}{\mathrm{mol}}\right]}\end{array}$ & $\ln A$ \\
\hline \multirow{3}{*}{ Arrhenius } & 10 & 41.68 & 13.77 & 51 & 15.59 & 112.15 & 26.63 \\
& 15 & 52.49 & 17.81 & 70.68 & 20.33 & 102.61 & 24.20 \\
& 20 & 25.66 & 9.60 & 54.62 & 16.31 & 78.33 & 19.31 \\
\hline Kissinger & & 47.35 & 04.16 & 86.37 & 09.31 & 91.06 & 07.01 \\
\hline Kim-Park & & 41.20 & 17.98 & 78.19 & 23.70 & 81.49 & 21.72
\end{tabular}

data. From the slope, the activation energy $\left(E_{\mathrm{a}}\right)$ for all stages were calculated and listed in Table II. Activation energies of the decomposition complex were also calculated by Kissinger and Kim-Park. Both methods yield similar calculation results, which are therefore reasonable (Table II).
The Flynn-Wall plots for three different heating rates against the temperature for the stages I, II, and III are shown in Figs. 5-7, respectively, and the straight lines obtained are nearly parallel to each other. At each heating rate, the temperatures were determined corresponding to degree of conversion $\alpha$ within the range 0.1 to 0.9 in intervals of 0.1 . Activation energy $\left(E_{\mathrm{a}}\right)$ is calculated from the slope of $\ln \beta$ versus $1 / T$ for a fixed mass loss and it is given in Table III. We have also calculated activation energies by the Friedman method for all the three stages and it is given in Table III. The calculated values of the activation energy in the Flynn-Wall method very well agree with the Friedman. The values of activation energy which are within the range $<60 \mathrm{~kJ} \mathrm{~mol}^{-1}$ as expected for removal of weakly bound water of crystallization from such compounds [37, 38]. The dependence of effective activation energy $\left(E_{\mathrm{a}}\right)$ on the degree of conversion $(\alpha)$ for non-isothermal decomposition of BNPM obtained by Flynn-Wall, Friedman method are clearly depicted in Fig. 8.

TABLE III

Kinetic parameters of non-isothermal decomposition of BNPM by Flynn-Wall and Friedman method.

\begin{tabular}{|c|c|c|c|c|c|c|c|c|c|c|c|c|}
\hline \multirow[b]{3}{*}{$\alpha$} & \multicolumn{6}{|c|}{ Flynn-Wall } & \multicolumn{6}{|c|}{ Friedman } \\
\hline & \multicolumn{2}{|c|}{ Stage I } & \multicolumn{2}{|c|}{ Stage II } & \multicolumn{2}{|c|}{ Stage III } & \multicolumn{2}{|c|}{ Stage I } & \multicolumn{2}{|c|}{ Stage II } & \multicolumn{2}{|c|}{ Stage III } \\
\hline & $\begin{array}{c}E_{\mathrm{a}} \\
{\left[\mathrm{kJ} \mathrm{mol}^{-1}\right]}\end{array}$ & $\ln A$ & $\begin{array}{c}E_{\mathrm{a}} \\
{\left[\mathrm{kJ} \mathrm{mol}^{-1}\right]}\end{array}$ & $\ln A$ & $\begin{array}{c}E_{\mathrm{a}} \\
{\left[\mathrm{kJ} \mathrm{mol}^{-1}\right]}\end{array}$ & $\ln A$ & $\begin{array}{c}E_{\mathrm{a}} \\
{\left[\mathrm{kJ} \mathrm{mol}^{-1}\right]}\end{array}$ & $\ln A$ & $\begin{array}{c}E_{\mathrm{a}} \\
{\left[\mathrm{kJ} \mathrm{mol}^{-1}\right]}\end{array}$ & $\ln A$ & $\begin{array}{c}E_{\mathrm{a}} \\
{\left[\mathrm{kJ} \mathrm{mol}^{-1}\right]}\end{array}$ & $\ln A$ \\
\hline 0.1 & 65.01 & 16.85 & 109.33 & 15.65 & 135.32 & 23.66 & 91.14 & 35.81 & 113.25 & 13.62 & 139.95 & 36.07 \\
\hline 0.2 & 74.87 & 19.89 & 91.19 & 17.95 & 126.84 & 21.81 & 77.89 & 30.59 & 95.15 & 11.44 & 131.49 & 33.46 \\
\hline 0.3 & 71.36 & 18.67 & 64.85 & 11.54 & 113.98 & 19.07 & 74.39 & 28.92 & 68.84 & 8.27 & 118.65 & 30.22 \\
\hline 0.4 & 65.64 & 16.78 & 45.94 & 7.07 & 102.67 & 16.69 & 68.69 & 26.66 & 49.96 & 6.01 & 107.36 & 27.45 \\
\hline 0.5 & 65.14 & 16.53 & 28.69 & 3.19 & 91.39 & 14.34 & 68.20 & 26.18 & 32.74 & 3.93 & 96.09 & 24.77 \\
\hline 0.6 & 64.44 & 16.21 & 16.59 & 0.74 & 80.48 & 12.09 & 67.51 & 25.68 & 20.66 & 2.48 & 85.20 & 22.22 \\
\hline 0.7 & 64.24 & 16.06 & 8.26 & 0.65 & 71.56 & 10.28 & 67.32 & 25.37 & 12.34 & 1.48 & 76.29 & 20.13 \\
\hline 0.8 & 63.13 & 15.63 & 4.13 & 2.36 & 68.87 & 9.71 & 66.23 & 24.79 & 8.24 & 0.99 & 73.62 & 19.39 \\
\hline 0.9 & 60.67 & 14.78 & 6.29 & 1.42 & 67.82 & 9.45 & - & - & - & - & - & - \\
\hline
\end{tabular}

Dependence of effective activation energy $\left(E_{\mathrm{a}}\right)$ with extent of conversion $(\alpha)$ is used to identify its kinetic scheme i.e. these values are used for input to multistep for model fitting purposes [39]. It is seen from Fig. 8 that during stage I of decomposition, $E_{\mathrm{a}}$ is almost constant in the entire conversion range $(0.3-0.9)$. Hence, it is suggested that stage I is dominated by single step mechanism. During the stage II and stage III, $E_{\text {a }}$ varies strongly with extent of conversion indicating that the process is kinetically complex, i.e. multi-step mechanism [25]. $E_{\text {a }}$ decreases with the extent of conversion $\alpha$. The high value of $E_{\mathrm{a}}$ at the initial fraction reacted $(\alpha)$ indicates that the decomposed products are in equilibrium with the gaseous reactants. Effective activation energy is found to be higher for the stage III than the stage II. Kinetic compensation effect was observed in many isothermal processes. There is a linear relationship between $\ln A$ and $E_{\text {a }}$ viz.

$$
\ln A=a E+b \text {, }
$$

where $a$ and $b$ are called compensation parameters. Figure 9 shows the linear relationship between $\ln A$ and $E_{\mathrm{a}}$ and the obtained compensation parameters are given in Table IV. It is seen from Fig. 9 that the compensation effect is valid for the thermal decomposition of BNPM [40, 41].

Kinetic analysis of TG data based on the rate equation

$$
\beta \mathrm{d} \alpha / \mathrm{d} t=A \exp (-E / R T) f(\alpha),
$$

which states that the rate of the reaction is proportional to the rate coefficient with the Arrhenius temperature dependence and a function of the degree of conversion. The integral form of Eq. (9) is given by the expression 


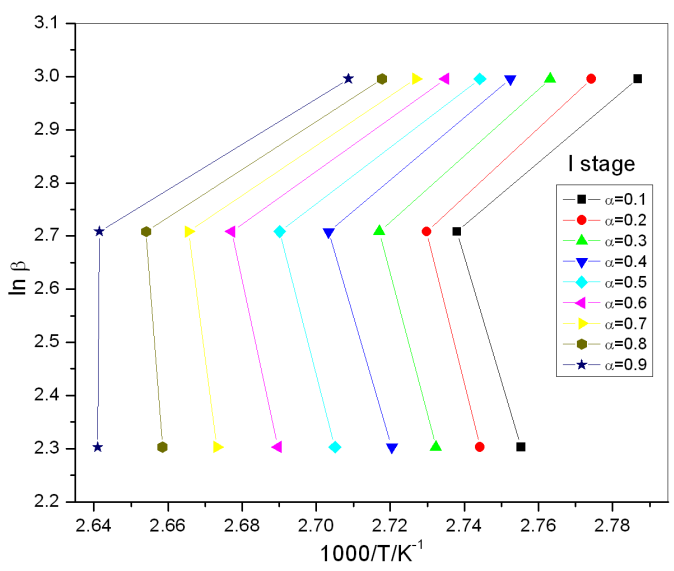

Fig. 5. Flynn-Wall plots for stage I in nitrogen atmosphere for the non-isothermal decomposition of BNPM.

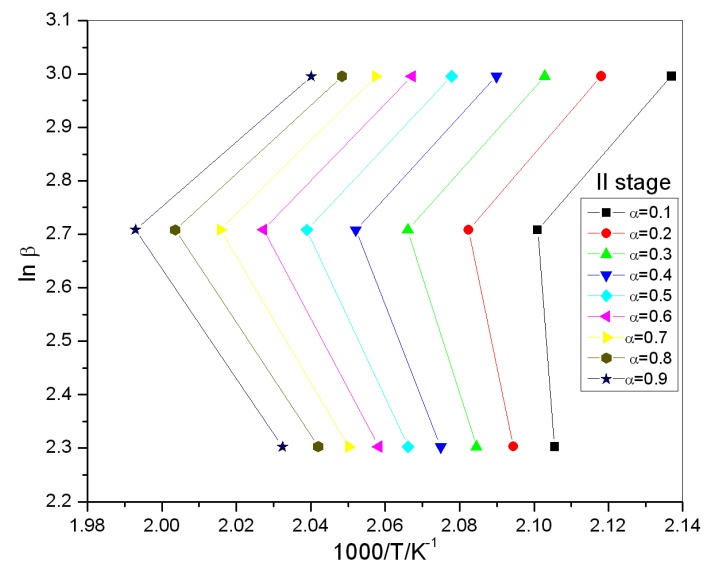

Fig. 6. As in Fig. 5, but for stage II.

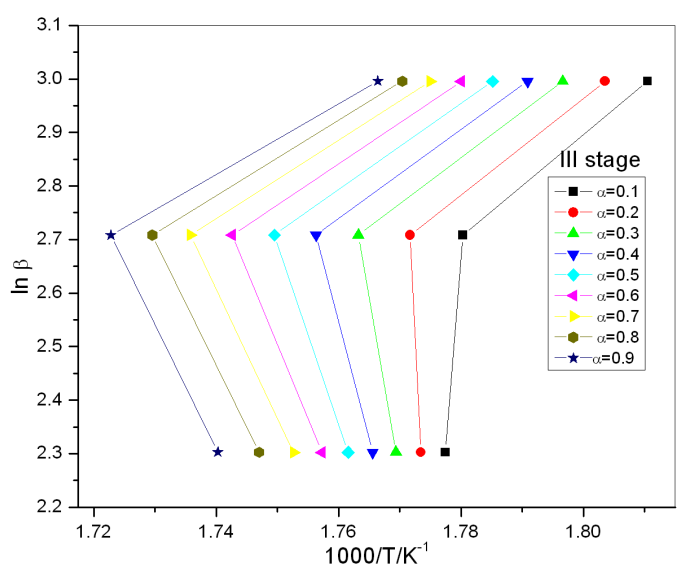

Fig. 7. As in Fig. 5, but for stage III.

TABLE IV

Compensation parameters of BNPM by Flynn-Wall and Friedman method.

\begin{tabular}{c|c|c|c|c|c|c}
\hline \hline Stages & \multicolumn{2}{|c|}{ Flynn-Wall method } & \multicolumn{3}{c}{ Friedman method } \\
\hline & $a$ & $b$ & $R$ & $a$ & $b$ & $R^{2}$ \\
\hline I & 6.7186 & 0.35638 & 0.988 & 3.66148 & 0.43568 & 0.994 \\
II & 2.3873 & 0.21706 & 0.988 & 0.00418 & 0.12028 & 1 \\
III & 4.75012 & 0.20939 & 0.999 & 1.15929 & 0.24671 & 0.999
\end{tabular}

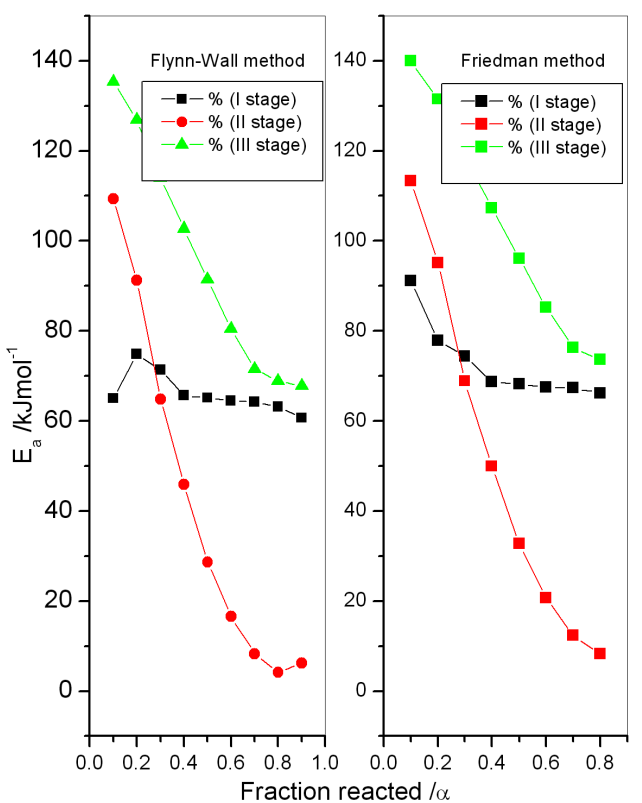

Fig. 8. Dependence of effective activation energy/ $E_{\mathrm{a}}$ versus $\alpha$ for stages I, II and III.

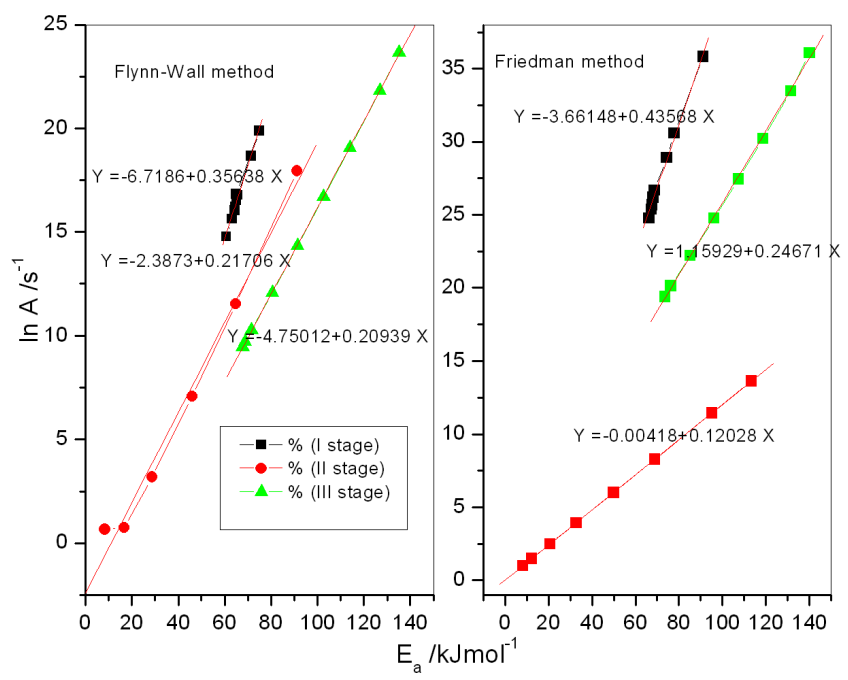

Fig. 9. Dependence of effective activation energy $\left(E_{\mathrm{a}}\right)$ versus $\ln A$ for stages I, II and III.

$\ln \left(g(\alpha) / T^{2}\right)=\ln ((A R / \beta E)(1-2 R T / E))-E / R T,(11)$ where $A$ is the pre-exponential factor, $E_{\mathrm{a}}$ is the effective activation energy and $R$ is the gas constant. Several researchers [42-45] reported the kinetic analysis by model fitting methods and dissociation mechanisms. Different models are used to fit the obtained kinetic curves in order to define the rate parameters and explain the mechanism of mass transfer. In the present study, all kinetic models (P4, P3, P2, P2/3, D1, F1, A4, A3, A2, D3, R3, $\mathrm{R} 2$, and D2) are tested for all the three stages. A plot of $\ln \left(g(\alpha) / T^{2}\right)$ versus $1000 / T$ gives a straight line when the correct $g(\alpha)$ function is used in the equation which is shown in Fig. 10. This $g(\alpha)$ function gives the mechanism of the reaction. 


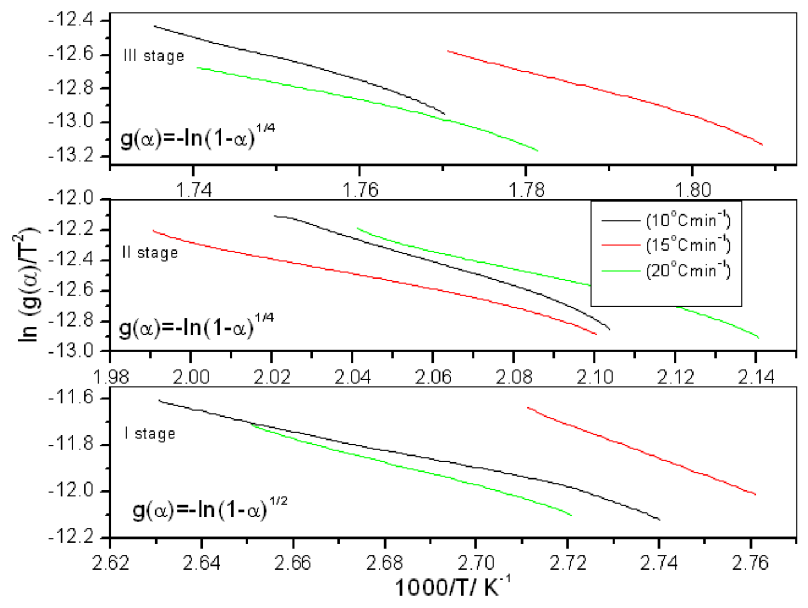

Fig. 10. Plots of $\ln \left(g(\alpha) / T^{2}\right)$ versus $1000 / T$ for stages I, II and III using TG data.

TABLE V

Kinetic parameters and possible rate controlling processes of decomposition of BNPM.

\begin{tabular}{c|c|c|c|c|c}
\hline \hline $\begin{array}{c}\text { Kinetic } \\
\text { model }\end{array}$ & $\begin{array}{c}\text { Heating } \\
\text { rate } \\
{\left[\frac{{ }^{\circ} \mathrm{C}}{\mathrm{min}}\right]}\end{array}$ & $\begin{array}{c}E_{\mathrm{a}} \\
{\left[\frac{\mathrm{kJ}}{\mathrm{mol}}\right]}\end{array}$ & $\ln A$ & $\begin{array}{c}\text { Correlation } \\
\text { coefficient } \\
R\end{array}$ & $\begin{array}{c}\text { Std. } \\
\text { deviation }\end{array}$ \\
\hline $\mathrm{A} 2$ & 10 & 35.1 & 0.518 & 0.99288 & 0.01142 \\
& 15 & 60.8 & 8.177 & 0.99962 & 0.00214 \\
& 20 & 42.9 & 1.986 & 0.99802 & 0.00481 \\
$\mathrm{~A} 4$ & 10 & 70.2 & 4.967 & 0.99395 & 0.01599 \\
& 15 & 46.1 & 1.178 & 0.99354 & 0.01438 \\
& 20 & 53.6 & 0.945 & 0.9930 & 0.01584 \\
$\mathrm{~A} 4$ & 10 & 115.6 & 11.702 & 0.99071 & 0.01381 \\
& 15 & 114.0 & 11.715 & 0.99272 & 0.0132 \\
& 20 & 95.0 & 7.232 & 0.98912 & 0.01454
\end{tabular}

Straight line with high correlation coefficient and low standard deviation values are selected to represent the possible controlling mechanism. The non-isothermal kinetic data of BNPM compound between the limit of $\alpha$ from 0 to 0.9 are fitted to all reaction models. More than one model (A2, A4, and A3) gave very good coefficient of linear equation lines with high correlation coefficient and low standard deviation value. However, by comparing the $E_{\mathrm{a}}$ values with the model-free method, it is found that I stage was accepted by Avrami-Erofeev's model (A2). The stages II and III were accepted by Avrami-Erofeev's (A4) model. The values of activation energy $\left(E_{\mathrm{a}}\right)$ and pre-exponential factor $(A)$, coefficient of correlation $R$ and standard deviation for three different heating rates for all stages are presented in Table V. The Arrhenius parameters $\left(E_{\mathrm{a}}, \ln A\right)$ of decomposition are highly variable, exhibiting a strong dependence on the reaction model chosen. Activation energy decreases with increasing heating rate in the stage III. Similarly, pre-exponential values are also changes with heating rate. The real activation energy for each stage of decomposition can be obtained only at lowest heating rate.

\section{Conclusion}

A detailed investigation on the non-isothermal studies of BNPM were carried out at three different heating rates 10,15 and $20^{\circ} \mathrm{C} \mathrm{min}^{-1}$ and have revealed that the decomposition occurs in three stages involving dehydration and decomposition. The activation energy obtained by model free methods like the Arrhenius, Flynn-Wall, Friedman, Kissinger and Kim-Park are comparable and yield almost similar results. It is found that the Flynn-Wall and KimPark are the most suitable method to find effective activation energy with high correlation coefficient. Effective activation is nearly constant for stage I whereas it varies strongly with extent of conversion for the stage II and III indicating that more than one competing reaction channels occurs during decomposition process i.e. the process is dominated by multi-step mechanism. The Arrhenius plot has been drawn to conclude the occurrence of compensation effect which is caused by the increased thermal lag at higher heating rates for the thermal decomposition of BNPM. The thermodynamic parameters suggest that the process is endothermic in nature which is confirmed by the DTG peak and reaction is fast and spontaneous one. From the results, it is concluded that the AvramiErofeev model (A2) describes the kinetics of crystallization and provides the better fit for the thermal decomposition of BNPM for the stage I and the Avrami-Erofeev model (A4) for the second and third stages.

\section{References}

[1] G.M. Crews, W. Ripperger, O.B. Kersebohm, J. Seeholzer, in: Ullmann's Encyclopedia of Industrial Chemistry, 6th ed. (electronic), Wiley-VCH, Weinheim 2001.

[2] J. Zieba-Palus, J. Mol. Struct. 511, 327 (1999).

[3] M. Kay, A.F. Price, I. Lavery, J. Fire Retardant Chem. 6, 69 (1979).

[4] J.R.A. Braodbent, M.M. Hirschler, Europ. Polym. J. 20, 1087 (1984).

[5] J.C. Spain, Annu. Rev. Microbiol. 49, 523 (1995).

[6] B. Likozar, R. Cerc Korosec, I. Poljansek, P. Ogorelec, P. Bukovec, J. Therm. Anal. Calorim. 109, 1413 (2012).

[7] P.P. Kalbende, M.V. Tarase, A.B. Zade, J. Chem. 1, 846327 (2013).

[8] M. Kulkarni, A. Chaudhari, Indian J. Chem. Technol. 13, 60 (2006).

[9] L. Costa, G. Camino, J. Therm. Anal. 34, 423 (1988).

[10] D.L. Yu, J.L. He, Z.Y. Liu, B. Xu, D.C. Li, M.J. Tioan, J. Mater. Sci. 43, 689 (2008).

[11] T. Nagaishi, M. Matsumoto, S. Yoshigana, J. Therm. Anal. 36, 55 (1990).

[12] Wen-Yi Chen, Yen-Zen Wang, Feng-Ehib Chang, J. Polym. Res. 11, 109 (2004).

[13] N. Kanagathara, M.K. Marchewka, S. Gunasekaran, G. Anbalagan, Acta Phys. Pol. A 126, 827 (2014). 
[14] N. Kanagathara, M.K. Marchewka, N. Sivakumar, K. Gayathri, N.G. Renganathan, S. Gunasekaran, G. Anbalagan, J. Therm. Anal. Calorim. 112, 1317 (2013).

[15] K. Siimer, P. Cristjanson, T. Kaljuvee, T. Pekh, I. Lasn, I. Saks, J. Therm. Anal. Calorim. 92, 19 (2008).

[16] N. Kanagathara, N.G. Renganathan, M.K. Marchewka, N. Sivakumar, K. Gayathri, P. Krishnan, S. Gunasekaran, G. Anbalagan, Spectrochim. Acta A 101, 112 (2013).

[17] A.I. Balabanovich, Thermochim. Acta 435, 188 (2005).

[18] S. Zhaou, M. Ning, Y. Xu, J. Shu, C. Wang, Y. Hu, G.E. Shaolin, Z. Tian, S.H.E. Shike, H.E. Qing, J. Therm. Anal. Calorim. 112, 1269 (2013).

[19] X. Wang, Y. Hu, L. Song, H. Yang, B. Yu, B. Kandola, D. Deli, Thermochim. Acta 543, 156 (2012).

[20] M. Roth, C.S. Zinger, U. Mueller, H. Schmidt, J. Anal. Appl. Pyrol. 79, 306 (2007).

[21] J.M. Filipovic, J.S. Velickovic, Z.U. Batalovic, M.D. Trifunovic, Thermochim. Acta 149, 341 (1989).

[22] X.G. Li, J. Appl. Polym. Sci. 74, 2016 (1999).

[23] S. Vyazovkin, A.K. Burnham, M.J. Craida, A.L. Perez Maqueda, C. Popescu, N. Sbirrazzuoli, Thermochim. Acta 520, 1 (2011).

[24] M.E. Brown, N. Maciejewski, S. Vyazovkin, R. Nomen, J. Sempere, A. Burnham, J. Opfermann, R. Strey, H.L. Anderson, A. Kemmler, R. Keuleers, J. Janssens, H.O. Desseyn, Chao-Rui Li, T.B. Tang, B. Roduit, J. Malek, T. Mitsuhashi, Thermochim. Acta 355, 125 (2000).

[25] N. Kanagathara, G. Chakkaravarthi, M.K. Marchewka, S. Gunasekaran, G. Anbalagan, Acta Crystallogr. E 68, o2286 (2012).

[26] N. Kanagathara, M.K. Marchewka, S. Gunasekaran, G. Anbalagan, J. Opto Electron Adv. M 16, 1436 (2014).

[27] Pratibha Srivastava, I.P.S. Kapoor, G. Singh, Indian J. Chem 46A, 1277 (2007).

[28] J.H. Flynn, L.A. Wall, J. Polym. Sci B Polym. Lett. 4, 323 (1966).
[29] H.L. Friedman, J. Polym. Sci. Part C 6183, 183 (1965).

[30] H.E. Kissinger, Anal. Chem. 27, 1702 (1957).

[31] S. Kim, J.K. Park, Thermochim. Acta 264, 137 (1995).

[32] V. Sangeetha, K. Gayathri, P. Krishnan, N. Sivakumar, N. Kanagathara, G. Anbalagan, J. Therm Anal. Calorim. 117, 307 (2014).

[33] V. Sangeetha, M. Govindarajan, N. Kanagathara, M.K. Marchewka, S. Gunasekaran, G. Anbalagan, Spectrochim. Acta Part A 125, 252 (2014).

[34] V. Sangeetha, M. Govindarajan, N. Kanagathara, M.K. Marchewka, S. Gunasekaran, G. Anbalagan, Spectrochim. Acta Part A 118, 1025 (2014).

[35] V. Sangeetha, M. Govindarajan, N. Kanagathara, M.K. Marchewka, M. Drozd, G. Anbalagan, J. Mol. Struct. 1054-1055, 307 (2013).

[36] S.M. Shin, S.H. Kim, Macromol. Res. 17, 149 (2009).

[37] B.A.A. Balboul, A.M. El-Roudi, E. Samir, A.G. Othman, Thermochim. Acta 387, 109 (2002).

[38] M.E. Brown, D. Doliimore, A.K. Galwey, in: Comprehensive Chemical Kinetics, Eds. C.H. Banford, C.F.H. Tipper, Elsevier, Amsterdam 1980.

[39] R. Jeya, T.L. Lekshman, M. Jose, S.J. Das, J. Therm. Anal. Calorim. 103, 845 (2011).

[40] M.E. Brown, A.K. Galwey, Thermochim. Acta 173 83 (2002).

[41] P. Budrugeac, E. Segal, J. Therm. Anal. Calorim. 62, 227 (2000)

[42] B. Jankovit, S. Mentus, A. Jantovit, J. Phys. Chem. Solids 69, 1923 (2008).

[43] S. Vyazovkin, I. Dranca, Macromol. Chem. Phys. 207, 20 (2006).

[44] C. Alzine, A. Sbirrazzuoli, A. Mija, J. Phys. Chem. B 114, 12480 (2010).

[45] Pratibha Srivastava, I.P.S. Kapoor, G. Singh, Indian J. Eng. Mater. S 16, 423 (2009). 